\title{
A Propensão das Famílias a Pagar por Leitura: Uma Análise Fundamentada nas Pesquisas de Orçamentos Familiares (POF) nas Regiões Metropolitanas entre 1996 e 2009
}

The Willingness to Pay for Reading: An Analysis from Household Budget Surveys in the Metropolitan Regions of Brazil from 1996 to 2009

\author{
Alexandre Nunes de Almeida ${ }^{a}$ \\ Lívia Rodrigues Spaggiari Souzab
}

\begin{abstract}
Resumo: O objetivo do presente trabalho foi analisar quais são os principais determinantes da propensão a pagar por material de leitura com base nas Pesquisas de Orçamentos Familiares em regiões metropolitanas brasileiras entre 1996 e 2009. Entre os principais resultados, observou-se que as mulheres têm maior probabilidade de despender com livros e menor com jornais e revistas em relação aos homens. Possuir cartão de crédito e acesso à internet aumenta a probabilidade de despender com leitura. Também foram encontradas diferenças significativas quanto aos gastos com leitura entre as regiões do país, quanto a renda e quanto à idade e quanto a posição domiciliar do indivíduo.
\end{abstract}

Palavras-chave: Leitura; Dispêndio; Pesquisa de Orçamentos Familiares; Modelos Probits. Classificação JEL: I25; R21; Z10

\begin{abstract}
The objective of this study was to analyze the main determinants of willingness to pay for reading from 1996 to 2009 in the major metropolitan regions of Brazil. Among the main results, women are more likely to spend with books and less with newspapers and magazines compared to men. Having credit card and internet access increase the likelihood of spending with reading. Significant differences were also found regarding to reading expenses between regions, income, age and household status of the individual.
\end{abstract}

Keywords: Reading; Expenditures; Household Budget Surveys; Probit Models.

\footnotetext{
${ }^{a}$ Professor Associado do Departamento de Economia, Administração e Sociologia da Esalq/USP.

E-mail: alex.almeida@usp.br

b Doutora em Demografia pela Unicamp. Email: spaggiari.livia@gmail.com
} 


\section{Introdução}

A sociedade globalizada em que vivemos exige de seus cidadãos uma capacidade reflexiva e uma absorção de conhecimentos mais acelerada, a fim de que a adaptabilidade às tecnologias insurgentes não seja uma barreira ao desenvolvimento. Não obstante, as capacidades reflexivas e críticas são alcançadas, além de outros meios, através do hábito da leitura. A atualização cultural, o próprio prazer ou gosto proveniente de se adquirir um novo conhecimento sem precisar ir muito longe, a exigência acadêmica pela leitura de textos técnicos, os motivos de cunho estritamente religiosos, a atualização profissional e as exigências exercidas pelo trabalho estão entre alguns dos motivos que levam o indivíduo a recorrer à leitura (FERREIRA, 1984; LASTRES; ALBAGLI, 1999).

Os objetos de leitura não se resumem unicamente a livros, revistas e a periódicos. Atualmente, com o avanço tecnológico, os e-books, bem como as cópias em papel ou até mesmo as cópias digitalizadas, são opções disponíveis aos leitores. A falta de praticidade e de acessibilidade não são mais barreias impostas à sociedade que é altamente simpática a recursos tecnológicos. No entanto, a renda disponível das famílias a expensas dessa natureza pode-se constituir sim um empecilho à prática da leitura.

Inciativas governamentais, que antes fomentavam o interesse principalmente dos grandes grupos editoriais, têm se tornado menos atrativas. $\mathrm{O}$ mercado de livros didáticos, que é financiado pelo governo federal, atualmente é um dos poucos que se mantém, mas não consegue fazer com que a expansão do mercado de leitura como um todo se sustente (ROSA; ODONE, 2006).

Através do PNC (Plano Nacional da Cultura) instituído pela Lei 12.343 de 2010 e do PNLL (Plano Nacional do Livro e Leitura) disposto pelo decreto 7.559 de 2011, o Governo Federal buscou contribuir executando ações incentivadoras à cultura visando obter em consonância uma maior democratização da leitura (BRASIL, 2018). No entanto, antes disso nenhum projeto com tamanha abrangência havia sido alvo de discussão na pauta governamental brasileira.

A importância da leitura e a maior valorização dessa prática observada no decorrer dos anos, desde 2001, de acordo com certos critérios são ilustradas pelas edições da pesquisa "Retratos da Leitura no Brasil" realizada pela Instituição Prólivro ${ }^{1}$. Empreendida pela primeira vez em janeiro de 2001, a referida pesquisa buscou revelar os hábitos de leitura dos brasileiros e procurou montar uma base de dados com vistas a fornecer informações para o planejamento do mercado e para o fomento de políticas públicas no Brasil. As quatro edições da pesquisa

\footnotetext{
${ }^{1}$ http://prolivro.org.br/home/index.php/atuacao/25-projetos/pesquisas/3900-pesquisa-retratos-daleitura-no-brasil-48
} 
supracitadas foram feitas respectivamente nos anos de 2001, 2008, 2011 e 2016, e, por sua vez, revelaram uma crescente aderência ao hábito da leitura por mulheres e por homens brasileiros, com destaque para as mulheres e jovens que constituem atualmente um promissor público alvo das editoras, dos escritores e das livrarias. Desde então, as regiões brasileiras foram analisadas por meio de amostragem populacional visando identificar o perfil dos leitores. Quesitos como região federativa, escolaridade e renda familiar constituíram em critério de análise a pesquisa ao longo das quatro edições. Entre os resultados mais importantes, observou-se que, entre 2011 e 2015, quanto maior o grau de instrução, mais livros o indivíduo lê por ano. Dentro das classes de renda A, B e C constatou-se que existem mais leitores que não leitores, enquanto entre indivíduos ranqueados nas classes de menor renda $\mathrm{D}$ e $\mathrm{E}$, a quantidade de leitores cresceu durante o período da pesquisa.

Relatório realizado pela Fenapro (Federação Nacional das Agências de Propaganda) em 2010 visou identificar o perfil dos leitores no Brasil, de acordo com a região, a faixa de renda familiar, a preferência por gênero literário (periódicos ou livros) e a frequência da leitura entre os entrevistados. Entre os principais resultados, Sul e Sudeste estavam à frente das demais regiões quando se fala em leitura de jornais e revistas. Os indivíduos na faixa etária entre 25 e 39 anos (50\%) costumam ler jornal em maior proporção, enquanto o público mais jovem, de 16 a 24 anos (44,6\%) costuma ler revistas. Para 47,1\% dos entrevistados, ler livros faz parte dos seus hábitos cotidianos, sendo que destes, 29,7\% leem apenas aos finais de semana e 17,4\% cultivam o hábito da leitura diária. Verificou-se também que na faixa de renda familiar mais alta (mais de 10 salários mínimos) a proporção de leitura de livros alcançou $67 \%$ dos entrevistados; já a leitura de jornais correspondeu a 65,2\%, e de revistas, 59,1\% (FENAPRO, 2010).

Estudos como os supracitados visando identificar o comportamento, bem como o perfil econômico do leitor e os possíveis impactos sofridos por ele mediante as mudanças nos cenários econômico, social, cultural e educacional são ainda escassos na literatura tanto nacional quanto internacional, apesar de constituírem um valioso instrumental para a formulação de políticas públicas. Esse fato, serviu como principal motivação para a elaboração do presente trabalho.

Um aspecto também bastante curioso levantado por pesquisas recentes é a diferença da dedicação à leitura dada por homens e por mulheres. Madalozzo (2008) menciona que dados divulgados pelo Inep (Instituto Nacional de Educação e Pesquisa) comprovam o melhor desempenho de meninas em disciplinas como língua portuguesa e literatura se comparadas aos meninos que cursam as mesmas séries escolares.

Um outro aspecto também a ser considerado entre as mulheres e os seus gastos com leitura diz respeito à sua maior dedicação a assuntos domésticos. 
Almeida et al. (2014) verificaram que as mulheres empregam maior parte de seu tempo às atividades que envolvem filhos e lar quando comparadas a seus cônjuges. Tal dispensa de maior tempo permite que se associe também uma maior destinação de suas rendas aos cuidados de filhos e lar, provendo a estes insumos necessários ao bem-estar e ao aprimoramento, respectivamente. Com isso, levantase o debate da diferença entre os sexos e as suas respectivas demandas por leitura, fato que será investigado em seção futura do presente trabalho.

De acordo com Riani e Marinho (2012), como se tratam de bens de consumo, análises das estruturas de orçamentos familiares permitem a realização de investigações que sejam capazes de apontar pistas sobre características das sociedades e particularidades regionais no que tange aos respectivos consumos. Um elemento importante para se levar em consideração nesse tipo de análise, ainda segundo as autoras, é a influência de elementos não exclusivamente socioeconômicos, mas também demográficos e culturais que possam influenciar sobre os padrões de consumo, tais como a composição e o tamanho das famílias, além das características demográficas do chefe do domicílio.

Este estudo procura, dadas as motivações supracitadas, observar por meio dos microdados obtidos das POF (Pesquisa de Orçamentos Familiares) para os anos de 1996, 2003 e 2009 quais são os determinantes demográficos e socioeconômicos que mais contribuem para o dispêndio com leitura dos indivíduos nas principais regiões metropolitanas brasileiras. Mais especificamente, pretende-se estimar as probabilidades dos referidos indivíduos despenderem com jornais e revistas, com livros, e a disposição a pagar também por livros didáticos.

Uma das hipóteses que norteia o presente trabalho é que o país tem vivido um momento econômico bastante distinto daquele de décadas passadas. Com a implementação do Plano Real em 1994 e a estabilidade da moeda, novas gerações de indivíduos experimentaram um quadro econômico até então inédito no país. Aspecto que foi e é de importância relevante na vida das famílias, dado que o controle sustentado da inflação permite ao chefe de família planejar por prazos maiores seu orçamento doméstico em função da renda obtida, melhorando o bemestar através do consumo de produtos nunca antes consumidos como: livros, internet, viagens e etc. (ALMEIDA; AZZONI, 2016).

Espera-se que através das análises propostas neste artigo seja possível inferir sobre "certos padrões de aquisição de consumo de jornais, revistas, livros e livros didáticos". E, também, se essa segregação de padrões permite identificar as principais variáveis determinantes para a demanda por livros em cada porção da população (levando em consideração sexo, renda, grau de escolaridade etc.), o que poderá ser um valioso subsídio à formulação de novas políticas de incentivo e de democratização da leitura.

A presente pesquisa encontra-se estruturada em cinco seções, sendo esta 
primeira uma breve introdução acerca do assunto. A Seção 2 descreve as fontes de dados utilizadas no estudo, encerrando com a estratégia empírica empregada. $\mathrm{Na}$ Seção 3, apresenta-se uma análise preliminar dos dados das POF referente aos hábitos de leitura dos brasileiros abarcando não somente as principais regiões metropolitanas analisadas posteriormente pela análise econométrica, mas também a título de curiosidade sobre os hábitos de leitura do restante do país cobertas pelas últimas POF disponíveis, 2002/03 e 2008/09. Os resultados econométricos encontrados são apresentados na Seção 4, e finalmente, na Seção 5, são apresentadas as considerações finais advogadas pelos autores.

\section{Dados e Estratégia Empírica}

\section{Dados}

Os dados a serem utilizados referem-se aos microdados das três últimas edições da Pesquisa de Orçamentos Familiares (POF) realizadas pelo IBGE nos períodos outubro/1995-setembro/1996, julho/2002-junho/2003 e maio/20o8maio/2009 ${ }^{2}$. As POF levantam informações sobre as condições do domicílio como: abastecimento de água, infraestrutura sanitária, número de cômodos, número de famílias (unidades de consumo) residindo no mesmo espaço domiciliar. Também são levantadas as características dos indivíduos como: sexo; nível de instrução; idade; frequência à escola; peso; altura e posição na família (chefe, cônjuge, filho, outro parente, agregado, pensionista, empregado doméstico e parente do empregado doméstico). Há também informações sobre as despesas com melhoria (reforma) do domicílio, com bens duráveis, etc.

De particular interesse para o estudo são as informações detalhadas sobre gastos com leitura, além das informações sobre gastos mensais e sobre recebimentos salariais e não salariais. Como as informações coletadas podem ter períodos de referência distintos, desde 7 dias até 12 meses, dependendo da natureza do registro, o IBGE disponibiliza coeficientes, que permitem que os valores sejam convertidos para valores anuais, ou seja, colocados em bases comparáveis (IBGE, 2010).

Foram entrevistadas 16.013 unidades domiciliares em 1995/96, 48.470 em 2002/o3 e 55.970 em 2008/o9, sendo que a primeira POF 96 cobriu apenas as nove regiões metropolitanas³, Goiânia e o Distrito Federal. Em função das variações dos preços nominais que ocorrem ao longo do período da coleta, geralmente 12 meses, o

\footnotetext{
2 Os microdados das POF estão gratuitamente disponíveis no site do IBGE através do link: http://downloads.ibge.gov.br/downloads_estatisticas.htm na pasta "Orçamentos Familiares".

3 Belém, Fortaleza, Recife, Salvador, Belo Horizonte, Rio de Janeiro, São Paulo, Curitiba e Porto Alegre.
} 
IBGE disponibiliza um deflator com data pré-definida pelo instituto ${ }^{4}$. Com isso, é possível comparar e analisar os registros em valores reais de acordo com o mês base definido pelo IBGE. A definição das amostras respectivas baseou-se no Censo Demográfico de 1991, no caso da POF 1995/96, e no Censo Demográfico de 2000 para as duas últimas edições (IBGE, 2004; IBGE 2010). Os fatores de expansão fundamentam-se na Contagem Populacional de 1996 e no Censo Demográfico de 2000.

O dispêndio com leitura, a ser investigado pelo estudo, está presente no questionário de despesa individual das POF. Portanto, será considerado como leitor o indivíduo que declarou a aquisição "compra" de algum produto classificado como bem de leitura segundo o IBGE. Naturalmente, pela pesquisa, não é possível saber se a compra desse bem foi para uso do próprio consumidor ou para algum outro membro da família, o que representa uma das limitações no escopo do estudo. Limitação igualmente estendida na identificação do público leitor para aqueles que obtiveram o material de leitura por meio de doação, gratuitamente da Internet, ou por empréstimos.

Nos microdados das POF, cada bem despendido é identificado através de um código numérico, assim como seu respectivo valor pago. Dessa forma, os produtos identificados como material de leitura foram então agrupados em três categorias, a saber: 1) jornais e revistas; 2) livros; e 3) livros técnicos e didáticos. O Quadro 1 no Apêndice ilustra quais bens foram considerados na análise dentro de cada grupo.

\section{Modelo Probit}

A escolha do método econométrico a ser utilizado se deu com base na própria natureza dos dados. Por exemplo, ao estimar modelos de acesso a um produto ou a um serviço espera-se que nem toda a população queira fazê-lo pois não possuem a necessidade de assim proceder (ANDRADE; LISBOA, 2001). Na literatura, essas respostas nulas são interpretadas como um processo de escolha individual e ao usar métodos mais tradicionais na análise de regressão como o conhecido mínimos quadrados ordinários (MQO), o resultado é a produção de estimativas inconsistentes e viesadas (GREENE, 2003). Portanto, como as variáveis dependentes a serem utilizadas nas regressões serão assumidas como binárias, isto é, assumem valores o (não comprou o bem) ou 1 (comprou), modelos de estimação não-lineares denominados probits ou logits são mais adequados a esses casos (GREENE, 2003).

Para o presente trabalho, o uso desses métodos implica em medir apenas a probabilidade (intenção) de efetuar algum dispêndio com produtos relacionados à

\footnotetext{
4 As datas de referência das POFs 95, 03 e o9 são 15 de setembro de 1996, 15 de janeiro de 2003 e 15 de janeiro de 2009, respectivamente.
} 
leitura, e não à quantidade (dos valores pagos) que está sendo consumida pelos indivíduos. Nesse último caso, analisar econometricamente não somente as quantidades consumidas, mas também as informações referentes às observações censuradas, procedimentos como o de seleção amostral de Heckman ou de Tobit estão entre os mais adequados (CAMERON; TRIVEDI, 2005). A supracitada análise foge do escopo do trabalho e é deixada para estudos futuros.

Considere um vetor $\mathrm{x}$ que seja constituído de um conjunto de fatores exógenos que explicam a decisão de um indivíduo i efetuar o dispêndio com leitura ou não. Esses fatores constituem-se como variáveis dependentes dentro do modelo.

Se o indivíduo efetuou gasto com leitura, o valor da variável dependente assume valor " 1 "; caso contrário, assume valor "o".

Assim, dado que o vetor $\mathrm{x}$ de variáveis exógenas procura explicar a decisão do indivíduo e os parâmetros $\beta$ s refletem o impacto das mudanças em $\mathrm{x}$ na probabilidade de efetuar o gasto ou não com material de leitura, essa probabilidade pode ser medida como:

$$
\operatorname{Pr}(Y=1)=F\left(\beta^{\prime} x\right)
$$

ou como:

$$
\operatorname{Pr}(Y=0)=1-F\left(\beta^{\prime} x\right)
$$

Nesse caso, define-se a esperança de Y como sendo:

$$
\mathrm{E}(\mathrm{Y})=\operatorname{Pr}(Y=1)=F\left(\beta^{\prime} x\right)
$$

onde $F(\cdot)$ é a função que segue uma distribuição normal.

A estimação dos parâmetros é então feita utilizando-se o método de máxima verossimilhança, em que a função de verossimilhança é dada por:

$$
\operatorname{Pr}\left(Y_{1}=y_{1}, Y_{2}=y_{2}, \ldots, Y_{n}=y_{n}\right)=\mathcal{L}=\prod_{i=1}^{n}\left[F\left(\beta^{\prime} x_{i}\right)\right]^{y_{i}}\left[1-\left[F\left(\beta^{\prime} x_{i}\right)\right]^{1-y_{i}}\right.
$$

$\mathrm{O}$ efeito que uma mudança de qualquer característica presente no vetor $\mathbf{x}$ causa à probabilidade de $\mathrm{Yi}=1$ não é $\beta$, mas sim a função de densidade da distribuição normal f vezes $\beta$, isto é:

$$
\frac{\partial E(Y)}{\partial x}=f\left(\beta^{\prime} x\right) \beta
$$

o qual é denominado efeito marginal (GREENE, 2003). 


\section{Análise Preliminar dos Dados}

A Tabela 1 apresenta a população total do Brasil e o percentual de homens e de mulheres que efetuaram algum dispêndio com leitura (jornais e revistas, livros não técnicos e livros didáticos) entre os anos de 1996, 2003 e 2009. Observa-se que o percentual de consumidoras leitoras em 2009 foi maior que o percentual de consumidores leitores masculinos em todas as regiões do país. Entretanto, essa diferença percentual já não foi tão expressiva em 2003. Várias hipóteses podem ser levantadas, incluindo a de que: mulheres têm exibido um nível de escolaridade médio maior que o dos homens; e que elas passaram a frequentar mais livrarias como uma forma de incentivar seus filhos; e apresentá-los ao hábito da leitura. Esses pontos de vista foram discutidos pela última edição da pesquisa realizada pelo Instituto Pró-livro em $2016^{5}$.

A Tabela 2 ilustra para diferentes classes de renda, entre 1996 e 2009, a renda mensal a preços constantes de 2015, o percentual da renda familiar gasto com algum material de leitura, e totalizando $100 \%$ a distribuição percentual desse dispêndio para três grupos de bens de leitura considerados. A soma de todos os gastos mensais monetários é também usada como aproximação da renda monetária, e, também, para agrupar as famílias em oito classes de renda (octils). Os valores monetários foram deflacionados utilizando-se dos deflatores de rendimentos da PNAD-INPC propostos por Corseuil e Foguel (2002) tendo como base o ano de 2015, o último ano disponível da série e disponibilizada no site: www.ipeadata.gov.br ${ }^{6}$.

Pela abertura da Tabela 2, pode-se observar que em todos os anos analisados, o percentual gasto por mês com algum material de leitura não ultrapassa $1 \%$ da renda total em todas as classes. Na análise, observa-se também que esses percentuais para 1996 são maiores em relação a 2003 e a 2009. O octil 1 para 2003 é uma exceção. Um resultado esperado já que, como mencionado, o primeiro ano cobre apenas as nove principais regiões metropolitanas, o DF e Goiânia, onde a oferta de material de leitura para consumo, através de bancas de jornais, de livrarias etc., é muito provavelmente mais abundante que em outras partes do país.

\footnotetext{
5 http://prolivro.org.br/home/index.php/atuacao/25-projetos/pesquisas/390o-pesquisa-retratos-daleitura-no-brasil-48

${ }^{6}$ Os deflatores utilizados para os anos de 1996, 2003 e 2009 foram o,30, o,43 e o,68, respectivamente.
} 
Tabela 1: População total e percentual do número de pessoas que gastaram com algum tipo de leitura entre $1996^{*}$ e 2009 segundo o sexo no Brasil

\begin{tabular}{l|c|c|c|c|c|c}
\hline \multirow{2}{*}{\multicolumn{1}{c|}{ Regiões }} & \multicolumn{2}{|c|}{1996} & \multicolumn{2}{c|}{2003} & \multicolumn{2}{c}{2009} \\
\cline { 2 - 7 } & Homens & Mulheres & Homens & Mulheres & Homens & Mulheres \\
\hline Centro-Oeste & $\mathbf{1 . 2 7 5 . 6 5 3}$ & 1.392 .854 & 5.937 .835 & 5.997 .632 & 6.758 .475 & 7.053 .501 \\
\hline Nordeste & 3.807 .865 & 4.177 .163 & 23.687 .392 & 24.613 .767 & 25.943 .686 & 27.43 .459 \\
\hline Norte & 451.188 & 491.741 & 6.813 .299 & 6.613 .619 & 7.696 .164 & 7.613 .271 \\
\hline Sul & 2.545 .538 & $\mathbf{2 . 7 3 3 . 9 0 8}$ & 12.570 .177 & $\mathbf{1 2 . 8 4 7 . 2 5 8}$ & $\mathbf{1 3 . 2 0 5 . 4 1 2}$ & $\mathbf{1 4 . 1 3 0 . 7 7 2}$ \\
\hline Sudeste & 13.932 .158 & $\mathbf{1 5 . 5 2 7 . 8 1 6}$ & 36.051 .676 & 37.679 .817 & 38.871 .968 & 40.875 .539 \\
\hline Pop Total & $\mathbf{2 2 . 0 1 2 . 4 0 2}$ & $\mathbf{2 4 . 3 2 3 . 4 8 2}$ & 85.060 .378 & 87.752 .094 & 92.475 .706 & 97.107 .541 \\
\hline
\end{tabular}

Percentual de Consumidores Leitores

\begin{tabular}{l|c|c|c|c|c|c}
\hline & Homens & Mulheres & Homens & Mulheres & Homens & Mulheres \\
\hline Centro-Oeste & $17,7 \%$ & $10,5 \%$ & $18,7 \%$ & $18,4 \%$ & $12,3 \%$ & $13,6 \%$ \\
\hline Nordeste & $9,3 \%$ & $8,1 \%$ & $13,1 \%$ & $14,7 \%$ & $11,2 \%$ & $13,6 \%$ \\
\hline Norte & $11,9 \%$ & $10,4 \%$ & $12,5 \%$ & $12,4 \%$ & $8,2 \%$ & $9,5 \%$ \\
\hline Sul & $16,0 \%$ & $14,2 \%$ & $14,1 \%$ & $14,3 \%$ & $12,5 \%$ & $13,2 \%$ \\
\hline Sudeste & $12,4 \%$ & $11,3 \%$ & $11,6 \%$ & $13,6 \%$ & $10,3 \%$ & $12,9 \%$ \\
\hline Total & $15,6 \%$ & $10,5 \%$ & $15,5 \%$ & $16,0 \%$ & $11,5 \%$ & $13,2 \%$ \\
\hline \hline
\end{tabular}

*Inclui as regiões metropolitanas de Belém, Fortaleza, Recife, Salvador, Belo Horizonte, Rio de Janeiro, São Paulo, Curitiba, Porto Alegre, acrescido do DF e de Goiânia.

Fonte: Microdados das POF (elaboração dos autores).

A Tabela 2 permite sugerir também sobre a existência de um ponto de saciedade no consumo desses produtos entre as classes de renda. Observa-se que, para cada ano analisado, enquanto a renda aumenta, o percentual do gasto mensal com leitura também aumenta (até classe de renda 7), e diminui para o último octil. Relembrando a teoria, à medida que uma pessoa consome quantidades adicionais de um dado bem, a utilidade que se obtém dessas porções marginais de consumo vai crescendo inicialmente até que se atinja o máximo, e acaba por diminuir, também marginalmente, até desaparecer (lei da utilidade marginal decrescente). Quando a utilidade marginal se torna nula, diz-se que o indivíduo atingiu seu ponto de saciedade ou de saturação pelo consumo do bem em questão (PINDYCK; RUBINFIELD, 2013). Essa hipótese poderá ser corroborada pelo modelo econométrico proposto. 
Tabela 2: Gasto mensal domiciliar (R\$), parcela do gasto mensal em material de leitura (\%) e distribuição percentual de dispêndio com bens de leitura entre $1996^{*}$ e 2003 no Brasil por classes de renda $(R \$=$ Base 2015)

\begin{tabular}{|c|c|c|c|c|c|}
\hline $\begin{array}{c}\text { Classes de } \\
\text { Renda }\end{array}$ & $\begin{array}{l}\text { R\$ Média } \\
\text { Mensal }\end{array}$ & $\begin{array}{c}\text { Parcela } \\
\text { Mensal com } \\
\text { Leitura } \\
\text { (\%) da renda } \\
\end{array}$ & $\begin{array}{c}\text { Jornais } \\
\text { e Revistas } \\
\quad(\%)\end{array}$ & $\begin{array}{c}\text { Livros } \\
(\%)\end{array}$ & $\begin{array}{c}\text { Livros } \\
\text { Didáticos } \\
(\%)\end{array}$ \\
\hline \multicolumn{6}{|c|}{1996} \\
\hline Octil 1 & 356,73 & 0,40 & 65,1 & 15,7 & 19,2 \\
\hline Octil 2 & 759,00 & 0,55 & 68,3 & 9,2 & 22,4 \\
\hline Octil $3_{3}$ & $1.131,20$ & 0,68 & 69,3 & 16,7 & 14,1 \\
\hline Octil 4 & $1.562,06$ & 0,67 & 66,5 & 17,8 & 15,6 \\
\hline Octil 5 & $2.051,86$ & 0,67 & 53,3 & 25,1 & 21,7 \\
\hline Octil 6 & $2.960,63$ & 0,98 & 60,8 & 21,0 & 18,2 \\
\hline Octil 7 & $4.953,20$ & 1,01 & 46,6 & 30,8 & 22,6 \\
\hline Octil 8 & $14.369,71$ & 0,67 & 41,8 & 38,9 & 19,3 \\
\hline \multicolumn{6}{|c|}{2003} \\
\hline Octil 1 & 528,92 & 0,40 & 24,7 & 15,9 & 59,5 \\
\hline Octil 2 & $1.111,44$ & 0,50 & 29,0 & 26,0 & 45,0 \\
\hline Octil 3 & $1.529,89$ & 0,62 & 50,5 & 19,1 & 30,5 \\
\hline Octil 4 & $2.035,73$ & 0,59 & 42,6 & 29,1 & 28,3 \\
\hline Octil 5 & $2.716,03$ & 0,73 & 42,4 & 30,8 & 26,8 \\
\hline Octil 6 & $3 \cdot 713,13$ & 0,80 & 39,9 & 33,4 & 26,8 \\
\hline Octil 7 & $5.642,05$ & 0,81 & 37,4 & 39,4 & 23,2 \\
\hline Octil 8 & $12.826,57$ & 0,71 & 34,5 & 40,1 & 25,4 \\
\hline \multicolumn{6}{|c|}{2009} \\
\hline Octil 1 & 534,75 & 0,32 & 47,8 & 14,8 & 37,4 \\
\hline Octil 2 & $1.085,35$ & 0,39 & 48,8 & 21,6 & 29,6 \\
\hline Octil 3 & $1.487,12$ & 0,45 & 47,5 & 27,2 & 25,3 \\
\hline Octil 4 & $1.942,84$ & 0,48 & 46,1 & 26,6 & 27,3 \\
\hline Octil 5 & $2.501,65$ & 0,57 & 44,3 & 32,1 & 23,6 \\
\hline Octil 6 & $3 \cdot 379,92$ & 0,55 & 44,7 & 29,8 & 25,5 \\
\hline Octil 7 & $5.092,95$ & 0,72 & 42,1 & 34,3 & 23,6 \\
\hline Octil 8 & $12.699,57$ & 0,52 & 31,8 & 42,6 & 25,6 \\
\hline
\end{tabular}

*Inclui as regiões metropolitanas de Belém, Fortaleza, Recife, Salvador, Belo Horizonte, Rio de Janeiro,

São Paulo, Curitiba, Porto Alegre acrescido do DF e Goiânia.

Fonte: Microdados das POF (elaboração dos autores).

Ainda com base na supracitada Tabela 2, em 1996, pode-se observar uma tendência comum a todas classes de renda em despender parte considerável dos gastos com leitura em jornais e em revistas, a exemplo, destaca-se a classe de renda 
3 que gastou $69,3 \%$ de sua renda em jornais e em revistas e os 30,8\% restantes em livros didáticos (14,1\%) e não didáticos $(16,7 \%)$.

É interessante observar também que mesmo que a proporção gasta com jornais e revistas continue sendo expressiva dentro de cada ano da análise, quando a renda aumenta (a partir do octil 3), observa-se, entretanto, uma redução desse grupo de bens concomitante à elevação da proporção de gastos com o gênero literário clássico-narrativo (livros não didáticos).

O nível de escolaridade é claramente apontado pelas pesquisas do Instituto Pró-livro como fator determinante para a quantidade de leitura que cada indivíduo realiza em média. $\mathrm{O}$ referido estudo em sua $4^{\mathrm{a}}$ edição, por exemplo, aponta que pessoas com nível superior de educação leem mais livros por ano que as pessoas com menor grau de escolaridade (FAILLA, 2011). Essa afirmação é corroborada pela análise da Tabela 3. Entre 1996 e 2009, observa-se que entre consumidores leitores e não leitores, os primeiros têm em média mais anos de estudo do que os segundos.

Outrossim, verifica-se que, de forma prevalecente, as mulheres leitoras possuem maior grau de instrução que os homens também leitores. A essas constatações pode-se sugerir o fato de que mulheres com mais anos de escolaridade teriam o hábito da leitura como uma forma de influenciar seus filhos, ou ainda dizer que este hábito seria decorrente da sua crescente inserção no mercado de trabalho como constatado nas pesquisas do Instituto Pró-livro (FAILLA, 2011).

Conforme constatam Barros e Lam (1993), pessoas com rendas mais elevadas possuem níveis de escolaridade também mais elevados, existindo assim entre as duas variáveis renda e escolaridade uma relação de forte causalidade, uma vez que indivíduos com maior renda disponível podem investir mais em aprimoramento e em educação, em decorrência disso podem auferir rendas ainda maiores. A exemplo, como explicitado pela Tabela 3, para a oitava classe de renda os homens leitores em 2009 apresentavam em média 12,37 anos de escolaridades enquanto os de classe de renda mais baixa apresentavam 5,72 anos.

Relatório de pesquisa elaborado pela Fenapro em 2010 afirma que dos leitores de jornais e revistas, aproximadamente $25 \%$ disseram ter o hábito diário da leitura destes, enquanto $30 \%$ disseram o fazer semanalmente apenas. E isso difere do gasto que é realizado com livros (didáticos e não didáticos), geralmente irregular, ou que pelo menos não segue periodicidade tão determinada. Pessoas com rendas mais baixas, ainda segundo esse relatório, geralmente, preferem se atualizar por meio da mídia televisiva e por meio da radiodifusão. Ademais, vale salientar o papel que a internet exerceu contribuindo para a diminuição do consumo por produtos impressos (LOURENÇO, 2004). 
Tabela 3: Escolaridade média (anos de estudo) entre leitores e não leitores por classes de renda e por sexo entre $1996^{*}$ e 2009 no Brasil

\begin{tabular}{|c|c|c|c|c|}
\hline \multirow{2}{*}{ Classes de Renda } & \multicolumn{2}{|c|}{ Homens } & \multicolumn{2}{|c|}{ Mulheres } \\
\hline & Leitores & Não Leitores & Leitores & Não Leitores \\
\hline \multicolumn{5}{|l|}{ Octil 1} \\
\hline Em 1996 & 7,19 & 4,54 & 8,00 & 4,73 \\
\hline Em 2003 & 5,21 & 2,90 & 5,47 & 3,17 \\
\hline Em 2009 & 5,72 & 3,71 & 6,22 & 4,11 \\
\hline \multicolumn{5}{|l|}{ Octil 2} \\
\hline Em 1996 & 8,91 & 5,35 & 8,57 & 5,58 \\
\hline Em 2003 & 6,31 & 3,84 & 6,92 & 4,32 \\
\hline Em 2009 & 7,06 & 4,82 & 7,83 & 5,24 \\
\hline \multicolumn{5}{|l|}{ Octil $3_{3}$} \\
\hline Em 1996 & 8,49 & 5,69 & 9,18 & 6,17 \\
\hline Em 2003 & 7,07 & 4,41 & 7,50 & 4,66 \\
\hline Em 2009 & 7,77 & 5,44 & 8,56 & 5,77 \\
\hline \multicolumn{5}{|l|}{ Octil $4_{4}$} \\
\hline Em 1996 & 9,63 & 6,21 & 9,31 & 6,77 \\
\hline Em 2003 & 7,79 & 4,86 & 8,06 & 5,06 \\
\hline Em 2009 & 8,75 & 5,72 & 8,86 & 6,26 \\
\hline \multicolumn{5}{|l|}{ Octil 5} \\
\hline Em 1996 & 9,52 & 6,94 & 10,14 & 7,02 \\
\hline Em 2003 & 8,67 & 5,50 & 9,00 & 5,77 \\
\hline Em 2009 & 9,40 & 6,30 & 9,75 & 6,71 \\
\hline \multicolumn{5}{|l|}{ Octil 6} \\
\hline Em 1996 & 10,82 & 7,08 & 10,79 & 7,51 \\
\hline Em 2003 & 9,67 & 5,73 & 9,84 & 6,35 \\
\hline Em 2009 & 9,99 & 6,94 & 10,76 & 7,17 \\
\hline \multicolumn{5}{|l|}{ Octil 7} \\
\hline Em 1996 & 11,60 & 8,08 & 12,33 & 8,72 \\
\hline Em 2003 & 10,85 & 6,85 & 11,32 & 6,74 \\
\hline Em 2009 & 10,88 & 7,76 & 11,20 & 7,88 \\
\hline \multicolumn{5}{|l|}{ Octil 8} \\
\hline Em 1996 & 13,15 & 8,73 & 12,96 & 9,36 \\
\hline Em 2003 & 12,61 & 7,97 & 12,38 & 7,94 \\
\hline Em 2009 & 12,37 & 8,63 & 12,56 & 8,54 \\
\hline
\end{tabular}

*Inclui as regiões metropolitanas de Belém, Fortaleza, Recife, Salvador, Belo Horizonte, Rio de Janeiro, São Paulo, Curitiba, Porto Alegre acrescido do DF e Goiânia.

Fonte: Microdados das POF (elaboração dos autores).

Baseado ainda no que foi descrito por Lourenço (2004), assistindo às mudanças e ao surgimento das tecnologias da linguagem oral e escrita, bem como 
dos tipos móveis de tecnologias eletrônicas, espera-se uma alteração do modo de transmissão de informações, de leitura, de histórias e de formação de culturas na sociedade, e até mesmo nas preferências dos agentes. Grande parte da população na pesquisa da Fenapro disse preferir acessar jornais e revistas por meio de seus exemplares online, por motivos de comodidade e até mesmo por preço (FENAPRO, 2010).

Tabela 4: Gasto médio por mês ( $\mathrm{R} \$$ = Base 2015) por tipo de leitura e por sexo entre 1996* e 2009 no Brasil

\begin{tabular}{|c|c|c|c|c|c|c|}
\hline \multirow[t]{2}{*}{ Classes de Renda } & \multicolumn{3}{|c|}{ Homens } & \multicolumn{3}{|c|}{ Mulheres } \\
\hline & $\begin{array}{l}\text { Jornais e } \\
\text { Revistas } \\
\end{array}$ & Livros & $\begin{array}{c}\text { Livros } \\
\text { Didáticos } \\
\end{array}$ & $\begin{array}{l}\text { Jornais e } \\
\text { Revistas }\end{array}$ & Livros & $\begin{array}{c}\text { Livros } \\
\text { Didáticos } \\
\end{array}$ \\
\hline & \multicolumn{6}{|c|}{1996} \\
\hline Octil 1 & 12,22 & 1,87 & 2,96 & 6,76 & 3,62 & 3,28 \\
\hline Octil 2 & 16,26 & 1,42 & 3,35 & 10,16 & 2,63 & 6,58 \\
\hline Octil 3 & 20,29 & 4,58 & 3,11 & 15,23 & 4,09 & 4,56 \\
\hline Octil 4 & 21,03 & 3,88 & 3,22 & 12,82 & 5,68 & 5,24 \\
\hline Octil 5 & 16,65 & 5,55 & 6,27 & 15,36 & 10,09 & 6,88 \\
\hline Octil 6 & 29,99 & 6,81 & 8,69 & 28,42 & 14,57 & 8,91 \\
\hline Octil 7 & 33,38 & 16,88 & 14,47 & 19,29 & 19,63 & 11,66 \\
\hline Octil 8 & 41,20 & 38,74 & 20,72 & 38,75 & 35,37 & 15,64 \\
\hline \multicolumn{7}{|c|}{2003} \\
\hline Octil 1 & 2,24 & 1,36 & 4,39 & 1,97 & 1,35 & 5,79 \\
\hline Octil 2 & 4,03 & 2,99 & 4,74 & 2,97 & 3,06 & 6,22 \\
\hline Octil 3 & 9,04 & 3,34 & 4,31 & 7,46 & 2,73 & 5,23 \\
\hline Octil 4 & 8,40 & 4,08 & 5,02 & 6,09 & 5,44 & 4,53 \\
\hline Octil 5 & 11,98 & 7,02 & 5,53 & 7,57 & 6,75 & 6,32 \\
\hline Octil 6 & 15,33 & 11,54 & 8,05 & 9,18 & 9,70 & 8,59 \\
\hline Octil 7 & 16,73 & 14,12 & 8,93 & 15,35 & 19,36 & 11,02 \\
\hline Octil 8 & 24,45 & 31,42 & 17,46 & 22,63 & 21,47 & 16,94 \\
\hline \multicolumn{7}{|c|}{2009} \\
\hline Octil 1 & 5,46 & 2,07 & 4,08 & 2,81 & 2,10 & 3,38 \\
\hline Octil 2 & 6,75 & 2,52 & 3,79 & 4,95 & 3,45 & 4,28 \\
\hline Octil 3 & 8,81 & 4,64 & 4,63 & 5,88 & 5,34 & 4,79 \\
\hline Octil 4 & 9,16 & 5,49 & 4,98 & 7,04 & 5,75 & 6,37 \\
\hline Octil 5 & 12,72 & 10,36 & 7,01 & 7,79 & 7,39 & 6,10 \\
\hline Octil 6 & 13,89 & 8,99 & 7,96 & 9,62 & 9,99 & 8,30 \\
\hline Octil 7 & 21,14 & 17,17 & 14,37 & 14,07 & 15,74 & 8,35 \\
\hline Octil 8 & 21,94 & 31,35 & 19,68 & 16,34 & 27,03 & 15,57 \\
\hline
\end{tabular}

*Inclui as regiões metropolitanas de Belém, Fortaleza, Recife, Salvador, Belo Horizonte, Rio de Janeiro, São Paulo, Curitiba, Porto Alegre acrescido do DF e Goiânia.

Fonte: Microdados das POF (elaboração dos autores). 
A Tabela 4, que separa os tipos de leitura por sexo e por classes de renda entre 1996 e 2009, mostra que o gasto mensal a preços constantes de $2015 \mathrm{com}$ revistas é sempre maior para os homens em relação às mulheres em todas as classes e nos três anos analisados. Por outro lado, com livros não didáticos, o dispêndio mensal feminino foi superior ao dispêndio mensal masculino em todas as classes, principalmente em 1996, que cobre as principais regiões metropolitanas do país. Homens das classes de renda 8 são uma exceção. No entanto, quando se analisa o território nacional, entre 2003 e 2009 , as diferenças por sexo desse último grupo de dispêndio já não são tão evidentes. Na mesma direção, são os gastos com livros didáticos, em que também não existe uma diferença marcante do dispêndio mensal desse grupo entre homens e mulheres entre 2003 e 2009.

Outro conceito simples, mas bastante interessante de ser observado é a análise do tipo elasticidade-renda da demanda. A elasticidade-renda da demanda mede, por sua vez, a variação percentual na quantidade demandada de um bem dada uma variação percentual na renda do consumidor. A demanda por leitura poderá ser elástica (sensível à variável em questão, a renda), inelástica (insensível à renda) ou unitária (a variação da quantidade dar-se-á na mesma proporção que a variação da renda das faixas) (PINDYCK; RUBINFIELD, 2013).

A Tabela 5 apresenta as elasticidades de renda da demanda por leitura das classes de renda obtidas econometricamente ${ }^{7}$. Os erros padrões reportados são robustos para heterocedasticidade e estão abaixo dos coeficientes entre parênteses. Ademais, para manter consistente a análise dos dados entre a POF 95/96 com as POF 02/03 e 08/o9, apenas observações individuais referentes às nove regiões metropolitanas, mais as observações de Goiânia e as do Distrito Federal das duas últimas POF foram utilizadas. A variável renda mensal foi convertida para escala logarítmica, no intuito de facilitar a interpretação de seus coeficientes após a realização dos testes econométricos, que passam a ser vistos como variações percentuais (GUJARATI, 2000).

Na Tabela 5, pode-se observar que para as faixas de renda 3, 5 e 6, aumentos de $1 \%$ nas respectivas rendas correspondem a aumentos maiores que $1 \%$ nos gastos com leitura. Quando se observa a variação da demanda por leitura das faixas de renda 1, 2, 4, 7 e 8 vê-se variações, porém, menores que para as faixas precedentes, abaixo de $1 \%$. Portanto, aumentos de $1 \%$ nas rendas dessas faixas não impactam na mesma proporção suas expensas com leitura.

Destaca-se que as menores elasticidades foram observadas para as duas classes totalmente opostas da distribuição, classes 1 e 8. Logo, em decorrência disso conclui-se que para as classes representadas pelos octils 1, 2, 4, e 8 têm-se uma

7 Modelo de regressão linear especificado como: Ln do Gastos com leitura em $\mathrm{R} \$=\alpha+\beta$ (Ln da Renda Mensal em R\$) + Binárias para Região e Ano + termo de erro. 
demanda por leitura menos elástica que para as classes 3, 5 e 6, sendo a classe 7 bastante próxima da elasticidade unitária.

Tabela 5: Elasticidade-Renda mensal da demanda por leitura por oito classes de renda entre 1996 e 2009 nas 9 RMs acrescido do DF e Goiânia

\begin{tabular}{c|c|c|c|c|c|c|c|c}
\hline \hline & \multicolumn{10}{|c}{ Classes de Renda } \\
\cline { 2 - 10 } & $\mathbf{1}$ & $\mathbf{2}$ & $\mathbf{3}$ & $\mathbf{4}$ & $\mathbf{5}$ & $\mathbf{6}$ & $\mathbf{7}$ & $\mathbf{8}$ \\
\hline $\begin{array}{c}\text { Ln da Renda } \\
\text { mensal }\end{array}$ & $\begin{array}{c}0,57^{*} \\
(0,13)\end{array}$ & $\begin{array}{c}0,81^{*} \\
(0,34)\end{array}$ & $\begin{array}{c}1,42^{*} \\
(0,41)\end{array}$ & $\begin{array}{c}0.94^{*} \\
(0,42)\end{array}$ & $\begin{array}{c}1.18^{*} \\
(0,44)\end{array}$ & $\begin{array}{c}1.19^{*} \\
(0,19)\end{array}$ & $\begin{array}{c}0,98^{*} \\
(0,17)\end{array}$ & $\begin{array}{c}0,32^{*} \\
(0,04)\end{array}$ \\
\hline Região (Binária) & Sim & Sim & Sim & Sim & Sim & Sim & Sim & Sim \\
\hline Ano (Binária) & Sim & Sim & Sim & Sim & Sim & Sim & Sim & Sim \\
\hline $\mathrm{N}$ & 1.642 & 1.862 & 2.287 & $\mathbf{2 . 5 8 9}$ & $\mathbf{2 . 4 2 1}$ & 4.040 & 4.068 & 4.909 \\
\hline $\mathrm{R}^{2}$ & 0,11 & 0,04 & 0,06 & 0,02 & 0,02 & 0,03 & 0,02 & 0,02 \\
\hline F teste & $30,2^{*}$ & $12,3^{*}$ & $22,31^{*}$ & $9,1^{* *}$ & $8,5^{* *}$ & $20,78^{*}$ & $13,2^{* *}$ & $18,0^{*}$ \\
\hline \hline
\end{tabular}

Fonte: Elaboração própria baseada nos dados da pesquisa.

\section{Resultados Econométricos}

A Tabela 6 mostra as definições para todas as variáveis utilizadas no modelo econométrico adotado. Para este exercício, foram considerados somente indivíduos com 10 anos ou mais de idade, e que possuíam no mínimo 1 ano de estudo, completos ou não. Similar ao recorte amostral adotado durante as estimações das elasticidades reportadas na Tabela 5, apenas residentes das 9 regiões metropolitanas (RMs de Belém, Fortaleza, Recife, Salvador, Belo Horizonte, Rio de Janeiro, São Paulo, Curitiba, Porto Alegre), acrescidos DF e Goiânia foram utilizados na análise.

No cálculo do gasto per capita domiciliar foi considerada como família aquela com uma ou mais unidades de consumo de acordo com a definição do IBGE (2010). No entanto, a quantidade de duas ou mais famílias vivendo no mesmo espaço domiciliar é praticamente insignificante nas POFs. Por exemplo, em 99,72\%, 99,80\%, e 99,73\% dos domicílios entrevistados pelas POF 95/96, POF 02/o3, e POF o8/o9, respectivamente, havia apenas uma família vivendo neles.

Relembrando, também, que todos os valores usados nas estimativas foram expandidos pelo fator de expansão (pesos) das amostras definido pelo IBGE, enquanto que no deflacionamento dos valores monetários do gasto per capita, foram utilizados para os anos de 1996, 2003 e 2009, respectivamente, os seguintes deflatores o,30, o,43 e o,68 como propostos por Corseuil e Foguel (2002) tendo como base $\mathrm{o}$ ano de 2015 .

A média e o desvio padrão das variáveis dependentes e independentes utilizadas análise como definidas na tabela 6 estão na Tabela Aı no apêndice. Em 
resumo, analisando apenas as variáveis independentes nos três anos considerados da análise, observa-se que o gasto per capita orbitou entre R\$846 e R\$ 972.

Entre 1996 e 2009, também, o tamanho das famílias diminui de 4,61 para 3,90 componentes por domicílio. Destes, de $35 \%$ a $40 \%$ eram compostos por indivíduos chefes, enquanto aproximadamente $21 \%$ eram cônjuges, $30 \%$ filhos e $10 \%$ por outros membros no domicílio como outros parentes ou agregado.

\section{Tabela 6: Definição das Variáveis}

\begin{tabular}{l|l}
\hline \hline Variáveis Dependentes & \\
\hline Jornais e Revistas & $=1$ se gastou com jornais e revistas \\
\hline Livros & $=1$ se gastou com livros não técnicos \\
\hline Livros técnicos & $=1$ se gastou com livros técnicos \\
\hline Variáveis Independentes & \\
\hline Gasto per capita & $=$ Gasto mensal familiar/número de componentes da família \\
\hline Moradores & $=$ Número de pessoas na família \\
\hline Chefe & $=1$ se é chefe do domicílio \\
\hline Cônjuge & $=1$ se é conjugue \\
\hline Filhos & $=1$ se é filho \\
\hline Outros & $=1$ se é outros parentes ou agregado no domicílio \\
\hline Sexo & $=1$ se é do sexo masculino \\
\hline Chefe_trab & $=1$ se chefe trabalha \\
\hline Cônjuge_trab & $=1$ se cônjuge trabalha \\
\hline Filhos_trab & $=1$ se filho trabalha \\
\hline Outros_trab & $=1$ se outro parente ou agregado trabalha \\
\hline Educação 3 & $=1$ se tem entre 1 e 3 anos de estudo \\
\hline Educação 7 & $=1$ se tem entre 4 e 7 anos de estudo \\
\hline Educção 12 & $=1$ se tem entre 8 e 12 anos de estudo \\
\hline Educação 15 & $=1$ se tem acima de 12 anos de estudo \\
\hline Cartão & $=1$ se tem cartão de crédito \\
\hline Internet & $=1$ se no domicílio tem internet \\
\hline Idade & $=$ idade do indivíduo \\
\hline Norte & $=1$ se a RM está localizada na região Norte \\
\hline Nordeste & $=1$ se a RM está localizada na região Nordeste \\
\hline Sudeste & $=1$ se a RM está localizada na região Sudeste \\
\hline Sul & $=1$ se a RM está localizada na região Sul \\
\hline Centro-Oeste & $=1$ se a RM está localizada na região Centro-Oeste \\
\hline
\end{tabular}

Fonte: Elaboração própria baseada nos dados da pesquisa.

Cerca de $47 \%$ dos indivíduos com 10 anos ou mais de idade entre 1996 e 2009 possuía entre 8 e 12 anos de estudo, enquanto aproximadamente $32 \%$ possuía entre 4 e 7 anos de estudo. A parcela com ensino superior, acima de 12 anos, era baixa no período coberto, menos do que $15 \%$. 
Quanto à localização geográfica, a maioria estava localizada nas regiões metropolitanas do Nordeste e Sudeste. A idade média dos respondentes orbitava em torno dos 35 anos entre 1996 e 2009, enquanto, o número de pessoas com cartão de crédito aumentou de forma expressiva, de $21 \%$ para $35 \%$. Já o número de pessoas com acesso à internet era relativamente baixo em 1996, 2\%, mas aumentou para $10 \%$ em 2009.

Na Tabela 7 estão apresentados coeficientes, erros padrões, efeitos marginais e testes das equações propostas dos modelos probits de dispêndio com: 1) jornais e revistas; 2) livros; e 3) livros técnicos. Variáveis binárias foram usadas para controle temporal dos dados. É importante relembrar também que os efeitos marginais reportados são as probabilidades, como demostrado na Seção 2.

O teste de razão de verossimilhança, que testa se todos os coeficientes de inclinação são iguais a zero, foi estatisticamente significativo para cada equação ao nível de $1 \%$, indicando que as variáveis pré-escolhidas explicam satisfatoriamente o dispêndio individual dos três grupos de leitura analisados nas 11 áreas das POF.

A renda per capita foi calculada dividindo-se a soma de todos gastos mensais monetários pelo número de pessoas presentes na família, e foi por fim transformada em valores logarítmicos para melhor ajustamento do modelo. O coeficiente dessa variável foi estatisticamente significativo e positivo em todas as três equações estimadas. Os resultados sinalizam que aumentos na renda elevam a probabilidade de despender com jornais e revistas, com livros e com livros técnicos. Os resultados negativos dos coeficientes da renda per capita ao quadrado, para os três grupos de leitura, também se mostraram estatisticamente significativos ao nível de $1 \%$ e permitiram corroborar a hipótese de que substanciais aumentos de renda sinalizam que o indivíduo pode ter atingido seu ponto de saciedade ou de saturação pelo consumo do bem de leitura em questão.

O resultado para o aumento no número de moradores se deu em direções opostas quando comparados com jornais e revistas, com livros e com livros técnicos. Por exemplo, a presença de cada um indivíduo a mais na família sugere que a probabilidade de comprar jornais e revistas ou livros não técnicos se reduz, enquanto a probabilidade de comprar livros técnicos/didáticos aumenta. Resultado último motivado, muito provavelmente, pela presença de filhos e de netos em idade escolar dentro da família.

Para os três grupos de produtos de leitura analisados, observou-se que a probabilidade de o chefe da família destinar suas expensas é maior do que a propensão a consumir pelos filhos (variável omitida). Um efeito oposto foi observado nos cônjuges quando se trata de jornais, de revistas e de livros. Esses indivíduos apresentaram uma probabilidade menor de consumo em relação aos filhos. Para livros técnicos a probabilidade dos cônjuges é positiva, no entanto, o 
coeficiente não se mostrou significativo aos níveis estatísticos de probabilidade de $1 \%, 5 \%$ ou $10 \%$.

Os resultados econométricos confirmam que a probabilidade dos homens gastarem em jornais e revistas é maior que das mulheres. No que diz respeito a livros e a livros didáticos essa probabilidade passa ser maior para as mulheres em relação aos homens.

Muito dos resultados observados, de certa forma, já eram esperados, uma vez que a leitura está estritamente relacionada à cultura e ao acúmulo de conhecimento, o que na maior parte das vezes são aspectos exigidos pelas empresas e pelas escolas. Para os chefes que trabalham, observou-se que existe uma probabilidade menor de comprar jornais e revistas, livros, e livros didáticos, quando comparados àqueles que não trabalham. Uma das hipóteses seria a de que o tempo disponível para o estudo e aquisição de conhecimento entre aqueles que trabalham é menor que entre os que não trabalham.

É senso comum, que a maior parte dos cônjuges de chefes de família são representados pelas mulheres. Na amostra usada pela presente análise, 93,5\% (não mostrado na Tabela 6) dos cônjuges eram formados por mulheres, e entre estes, o número de indivíduos trabalhando aumentou de $42 \%$ para $56 \%$ nas 11 áreas da pesquisa entre 1996 e 2009. Os resultados mostram que quando os cônjuges trabalham existe uma probabilidade maior de consumo com leitura nos três grupos analisados do que aqueles que não trabalham.

Os resultados dos efeitos marginais mostram que quanto maior o nível de escolaridade maior é a propensão a consumir objetos relacionados à leitura, como esperado. Observa-se, também, que quando a escolaridade aumenta, a disposição a pagar por livros técnicos aumenta mais lentamente do que a probabilidade de pagar por jornais e revistas, e por livros não didáticos. Esse resultado pode sugerir a existência de um mercado mais homogêneo quanto ao comércio de livros técnicos e didáticos resultante da falta de produtos substitutos para esse tipo de literatura, o que se traduz em menos opções para o consumo. Para pesquisadores e para estudantes não é difícil observar que o mercado editorial, principalmente o de livros técnicos com títulos nacionais, tem estado concentrado nas mãos de poucas grandes editoras (BRITTO, 2011).

O uso do cartão de crédito como moeda virtual se expandiu significativamente nas duas últimas décadas. Nas 9 RMs, DF e Goiânia, os usuários de cartão aumentaram de $21 \%$ para $35 \%$ entre 1996 e 2009 (Tabela 6). Pelos resultados econométricos, pode-se observar que quem possui cartão possui também maior probabilidade de gastar com material de leitura que aqueles que não o tem. 


\section{Tabela 7: Resultados dos Coeficientes do Modelos Probits e seus efeitos marginais $(\mathrm{dy} / \mathrm{dx})$ para três grupos de leitura selecionados ${ }^{\dagger}$}

\begin{tabular}{|c|c|c|c|c|c|c|}
\hline & \multicolumn{2}{|c|}{ 1) Jornais e Revistas } & \multicolumn{2}{|c|}{ 2) Livros } & \multicolumn{2}{|c|}{ 3) Livros Didáticos } \\
\hline & Coef & $\mathrm{dy} / \mathrm{dx}$ & Coef & $\mathrm{dy} / \mathrm{dx}$ & Coef & dy/dx \\
\hline $\begin{array}{l}\text { Ln dos gastos } \\
\text { mensal per capita }\end{array}$ & $1,21^{*}(0,07)$ & 0,11 & $0,68^{*}(0,06)$ & 0,110 & $0,66^{*}(0,07)$ & 0,059 \\
\hline $\begin{array}{l}\text { Ln dos gastos } \\
\text { mensal per capita }\end{array}$ & $-0,06^{*}(0,00)$ & $-0,006$ & $-0,03^{*}(0,00)$ & $-0,005$ & $-0,03^{*}(0,00)$ & $-0,003$ \\
\hline Moradores & $-0,06^{*}(0,00)$ & $-0,006$ & $-0,03^{*}(0,00)$ & $-0,005$ & $\mathrm{o}, \mathrm{Ol}^{*}(\mathrm{o}, \mathrm{OO})$ & 0,0009 \\
\hline Chefe & $0,30^{*}(0,02)$ & 0,032 & $0,30^{*}(0,02)$ & 0,052 & $0,37^{*}(0,03)$ & 0,036 \\
\hline Cônjuge & $-0,07^{*}(0,03)$ & $-0,006$ & $-0,09^{*}(0,02)$ & $-0,015$ & $0,01(0,03)$ & 0,001 \\
\hline Outros & $-0,13^{*}(0,04)$ & $-0,011$ & $-0,12^{*}(0,03)$ & $-0,018$ & $-0,11^{*}(0,03)$ & $-0,009$ \\
\hline Sexo & $0,21^{*}(0,01)$ & 0,021 & $-0,14^{*}(0,01)$ & $-0,022$ & $-0,10^{*}(0,01)$ & $-0,009$ \\
\hline Chef_trab & $-0,01(0,01)$ & $-0,001$ & $-0,03^{*}(0,01)$ & $-0,005$ & $-0,04^{*}(0,02)$ & $-0,004$ \\
\hline Cônjuge_trab & $0,09 *(0,03)$ & 0,009 & $0,18^{*}(0,02)$ & 0,032 & $0,16^{*}(0,02)$ & 0,016 \\
\hline Filhos_trab & $0,11^{*}(0,02)$ & 0,012 & $0,24^{*}(0,01)$ & 0,045 & $0,02(0,02)$ & 0,002 \\
\hline Outros_trab & $0,22^{*}(0,04)$ & 0,026 & $0,30^{*}(0,03)$ & 0,059 & $0,08^{*}(0,04)$ & 0,007 \\
\hline Educação 3 & $-0,71^{*}(0,03)$ & $-0,044$ & $-0,73^{*}(0,02)$ & $-0,079$ & $-0,53^{*}(0,03)$ & $-0,033$ \\
\hline Educação 7 & $-0,45^{*}(0,02)$ & $-0,039$ & $-0,60^{*}(0,01)$ & $-0,084$ & $-0,39^{*}(0,02)$ & $-0,031$ \\
\hline Educação 12 & $-0,17^{*}(0,01)$ & $-0,017$ & $-0,35^{*}(0,01)$ & $-0,056$ & $-0,31^{*}(0,01)$ & $-0,027$ \\
\hline Cartão & $0,13^{*}(0,01)$ & 0,013 & $0,19^{*}(0,01)$ & 0,033 & $0,12^{*}(0,01)$ & 0,012 \\
\hline Idade & $0,02^{*}(0,00)$ & 0,002 & $-0,00(0,00)$ & $-0,000$ & $\mathrm{o}, \mathrm{OI}^{*}(\mathrm{o}, \mathrm{OO})$ & 0,001 \\
\hline Idade $^{2}$ & $-0, \mathrm{OO}^{*}(\mathrm{o}, \mathrm{OO})$ & $-0,000$ & $-0, \mathrm{OO}^{*}(\mathrm{o}, \mathrm{OO})$ & $-0,000$ & $-0,00^{*}(0,00)$ & $-0,000$ \\
\hline Internet & $-0,04(0,02)$ & $-0,003$ & $0,04^{*}(0,02)$ & 0,008 & $0,05^{*}(0,02)$ & 0,005 \\
\hline Norte & $0,19^{*}(0,02)$ & 0,021 & $0,02(0,02)$ & 0,003 & $0,13^{*}(0,02)$ & 0,013 \\
\hline Nordeste & $-0,21^{*}(0,02)$ & $-0,019$ & $0,08^{*}(0,01)$ & 0,013 & $0,21^{*}(0,02)$ & 0,020 \\
\hline Sudeste & $0,23^{*}(0,01)$ & 0,024 & $-0,05^{*}(0,01)$ & $-0,008$ & $0,17^{*}(0,02)$ & 0,017 \\
\hline Centro-Oeste & $-0,04^{*}(0,02)$ & $-0,003$ & $-0,26^{*}(0,02)$ & $-0,037$ & $0,08^{*}(0,02)$ & 0,007 \\
\hline \multicolumn{7}{|l|}{ Binárias } \\
\hline Ano & Sim & & Sim & & Sim & \\
\hline Constante & Sim & & Sim & & Sim & \\
\hline$N$ & 112,605 & & 112,605 & & 112,605 & \\
\hline $\mathrm{R}^{2}$ & 0.13 & & 0.10 & & 0.09 & \\
\hline $\begin{array}{l}\text { Teste de razão } \\
\text { verossimilhança }\end{array}$ & $6.65^{*}$ & & $8.33^{*}$ & & $3.91^{*}$ & \\
\hline
\end{tabular}

${ }^{*}$ Significante ao nível de $5 \%$

†Erros Padrões robustos para heterocedasticidade estão entre parênteses ao lado dos coeficientes. Fonte: Elaboração própria baseada nos dados da pesquisa.

Observou-se que o hábito de gastar com algum material relacionado à leitura ainda é bastante heterogêneo entre as regiões. Por exemplo, ao olhar para jornais e revistas, constata-se que existe uma menor probabilidade de consumir esses itens por parte da população de leitores nas três RMs (Fortaleza, Recife e Salvador) da região Nordeste e de residentes do DF e de Goiânia quando estes são comparados 
aos indivíduos residentes nas duas RMs (Curitiba e Porto Alegre) da região Sul (variável omitida). Por outro lado, entre os residentes nas três RMs do Sudeste (Belo Horizonte, Rio de Janeiro e São Paulo) e da região Norte (RM de Belém) a probabilidade se apresenta positiva em relação a região Sul.

Quanto ao dispêndio relacionado a livros, os resultados sinalizam que a probabilidade de se consumir itens desse grupo é negativa entre os residentes nas RMs do Sudeste e do Centro-Oeste, e positiva para indivíduos residentes nas RMs nordestinas em relação aos residentes do Sul. Esse resultado pode estar refletindo a melhoria da infraestrutura de novas lojas, a presença de mais livrarias nas cidades ou até mesmo o acesso a maior variedade de livros disponíveis em bancas de jornais nessas capitais.

Já entre os livros didáticos ou técnicos, os resultados de todos os coeficientes das regiões consideradas foram positivos e estatisticamente significativos ao nível de $1 \%$, resultados que sinalizam que para esse grupo de bens a probabilidade de dispêndio pelos habitantes das duas RMs sulistas é menor que a dos habitantes residentes nas outras RMs.

Como conclusão, é reconhecido que o consumo de livros técnicos pode estar bastante correlacionado com a frequência às escolas e com a estrutura das universidades e das faculdades, o que é reconhecidamente heterogêneo pelo país. $\mathrm{E}$, pode-se ainda relacionar esse consumo a outros fatores como: a qualidade do ensino observado nas cidades, o material didático sugerido pelas instituições de ensino, a oferta deste material nas escolas públicas, a qualidade dos professores, a infraestrutura de ensino etc., além de novas hipóteses que poderão ser investigadas por estudos futuros.

\section{Conclusão}

Diante das análises construídas no presente trabalho confirmou-se que o aumento real da renda das famílias brasileiras, apesar de menor nestes últimos anos, traduziu-se em ganhos de poder de compra e em mudanças que foram positivas quanto aos hábitos de leitura, uma vez que se vive uma estabilidade da moeda nacional e um maior acesso às linhas de crédito, incluindo o crédito estudantil, entre outras políticas de inclusão social. Com isso, o padrão de consumo das famílias vem melhorado tanto quantitativamente quanto qualitativamente, visto que as classes mais baixas tiveram pela primeira vez acesso a bens que antes eram imanentes às classes mais altas.

A demanda por leitura, seja ela técnica, cultural ou meramente informativa, estabelece ligações fortes com o nível de renda possuído pelo leitor, que é 
diretamente proporcional ao nível de educação alcançado, valoriza mais ou menos atividade da leitura. Hipóteses corroboradas pela presente análise. Outras características observadas, também bastante pujantes, foram os diferentes padrões de consumo com leitura entre os sexos feminino e masculino, o exercício da atividade laboral e a posse de cartão de crédito e de serviços de internet.

Não obstante, evidenciou-se também que as facilidades trazidas pelas mídias televisivas e digital com seus telejornais de alcance nacional bem como regional, fez com que jornais, revistas e livros se tornassem opções e não mais fontes exclusivas de informação. No entanto, corroborou-se que aspectos culturais ainda exercem fortes influências quanto à forma de acesso preferível às notícias e ao conhecimento de cada indivíduo, o que reforça as diferenças observadas nos padrões regionais de consumo de leitura nas regiões metropolitanas analisadas.

Em suma, a influência dos fatores relacionados ao incentivo exercido pelos pais e pelas pessoas mais próximas e a todos demais fatores que ficaram fora do escopo deste trabalho, mas que, no entanto, contribuem para o aumento da demanda por leitura, são de extrema importância, e merecem mais dedicação nos trabalhos futuros. Os determinantes do consumo por leitura são também instrumentos valiosos de políticas públicas e permitem até mesmo a detecção de falhas diversas que sejam referentes ao sistema de ensino, ao acesso à cultura e até mesmo aos problemas estruturais do país.

\section{Referências}

ALMEIDA, A.N.; AZZONI, C.R. Custo de vida comparativo das regiões metropolitanas brasileiras: 1996-2014. Estudos Econômicos, v. 46, n. 1, p. 253-276, 2016. DOI: http://dx.doi.org/10.159o/o101-416146128aaa

ALMEIDA, M. V.; MELATO, F. C.; MARCONDES, G.; DE OLIVEIRA, M. C. Trabalho e Família na vida das mulheres brasileiras: novas e velhas tensões. Anais do XIX Encontro Nacional de Estudos Populacionais, ABEP. São Pedro, SP, 2014. Disponível em:

http://www.abep.org.br/ abeporgb/abep.info/files/trabalhos/trabalho_completo/T C-3-22-69o-623.pdf. Acesso em: 17 jan. 2016.

ANDRADE, M.V.; LISBOA, M. B. A economia da Saúde no Brasil. In:

Microeconomia e Sociedade no Brasil, Menezes-Filho, N. A. de, Lisboa, M. B. (Orgs). Fundação Getúlio Vargas/EPGE - Rio de Janeiro, 2001, p. 285-332.

BARROS, R. P.; LAM, D. Desigualdade de Renda, desigualdade em educação e escolaridade das crianças no Brasil. Revista de Pesquisa e Planejamento 
Econômico v. 23, n. 2, p. 191-218, 1993. Disponível em: http://ppe.ipea.gov.br/index.php/ppe/article/viewFile/826/763. Acesso em: 25 jan. 2016.

BRASIL. Plano Nacional de Cultura. 2018. Disponível em: http://pnc.cultura.gov.br/entenda-o-plano/. Acesso em: 10 abril. 2019

BRITTO, T. F. O Livro Didático, o Mercado Editorial e os Sistemas de Ensinos Apostilados. Textos para Discussão, SENADO FEDERAL v. 92. Brasília, DF, 2011. Disponível em: http://www12.senado.gov.br/publicacoes/estudoslegislativos/tipos-de-estudos/textos-para-discussao/td-92-o-livro-didatico-omercado-editorial-e-os-sistemas-de-ensino-apostilados. Acesso em: 26 jan. 2016.

CAMERON, A.; TRIVEDI, P. Microeconometrics: Methods and Applications. Cambridge: Cambridge University Press, 2005.

CORSEUIL, C.H.; FOGUEL, M. N. Uma Sugestão de Deflatores para Rendas Obtidas a Partir de Algumas Pesquisas Domiciliares do IBGE. Texto para Discussão, n. 897. Rio de Janeiro: Instituto de Pesquisa Econômica Aplicada, 2002. Disponível em: http://www.ipea.gov.br/portal/images/stories/PDFs/TDs/td_o897.pdf

FAILLA, Z. Retratos da Leitura no Brasil, Pró-Livro, 2011. Disponível em: http://www.prolivro.org.br/images/antigo/4095.pdf. Acesso em: 15 jan. 2016.

FENAPRO (FEDERAÇÃO NACIONAL DE AGÊNCIAS E PROPAGANDA), 2010. Disponível em: http://www.fenapro.org.br/relatoriodepesquisa.pdf. Acesso em: 15 jan. 2016.

FERREIRA, A. B. H. Enriqueça o Seu Vocabulário. 4ed. Rio de Janeiro: Nova Fronteira, 1984.

GREENE W. H. Econometric Analysis. 5ed, New Jersey: Prentice Hall, 2003. GUJARATI, D.N. Econometria Básica. zed. São Paulo: Makron Books, 2000. IBGE. (Instituto Brasileiro de Geografia e Estatística). Pesquisa de Orçamentos Familiares 2002-2003: Primeiros Resultados. Rio de Janeiro: IBGE, 2004.

Pesquisa de Orçamentos Familiares 2008-20o9: Despesas, Rendimentos e Condições de Vida. Rio de Janeiro: IBGE, 2010.

LASTRES, H.; ALBAGLI, S. Informação e Globalização na Era do Conhecimento. ed. Campus. Rio de Janeiro, RJ, 1999. Disponível em: http://www.redesist.ie.ufrj.br/livros/informacao-e-globalizacao-na-era-doconhecimento. Acesso em: 16 jan. 2016. 
LOURENÇO, M. S. Edição digital: aspectos e perspectivas da produção de eBooks no Brasil. I Seminário Brasileiro sobre Livro e História Editorial. UFF, Rio de Janeiro, RJ, 2004. Disponível em:

http://w.livroehistoriaeditorial.pro.br/pdf/marianasimoes.pdf. Acesso em 17 jan. 2016.

MADALOZZO, R. Gênero e Desigualdade. GV-executivo, v. 7, n. 6, 2008. Disponível em: https://rae.fgv.br/sites/rae.fgv.br/files/artigos/5392.pdf. Acesso em: 18 jan. 2016.

PINDYCK, R. S.; RUBINFELD, D.L. Microeconomia. 8ed. São Paulo: Pearson Education, 2013.

RIANI, J. de L. R.; MARINHO, K. R. L. Os padrões de consumo em educação e saúde segundo as características domiciliares e territoriais: um estudo a partir da PAD-MG 2009. Seminário de Economia Mineira. Belo Horizonte, MG, 2012.

Disponível em:

http://web.cedeplar.ufmg.br/cedeplar/seminarios/ecn/ecnmineira/2012/arquivos/ OS\%2oPADRÕES\%2oDE\%2oCONSUMO\%2oEM\%2oEDUCAÇÃO\%2oE\%2oSAÚD E].pdf. Acesso em: 16 jan. 2016.

ROSA, F. G. M. G; ODDONE, N. Políticas públicas para o livro, leitura e biblioteca. Ciência da Informação, v. 35, n. 3, p. 183-193, 2006. DOI: http://dx.doi.org/10.1590/So100-19652006000300017. 


\section{Apêndice}

\section{Lista dos Produtos das POF considerados como material de leitura}

\begin{tabular}{|c|c|c|}
\hline Jornais e Revistas & Livros & Livros Técnicos \\
\hline Jornal & Livros não-didáticos & $\begin{array}{l}\text { Assinatura de periódico técnico } \\
\text { Livro escolar de primeiro e }\end{array}$ \\
\hline Revista infantil & Coleção não-didáticos & segundo grau \\
\hline Fotonovela & Fascículo & $\begin{array}{l}\text { Livro escolar de } 1^{\mathrm{o}} \text { e } 2^{\mathrm{o}} \text { grau } \\
\text { Livro técnico, revista técnica }\end{array}$ \\
\hline Revista esportiva & Romance & didáticos \\
\hline Revista de moda & Bíblia & Livro técnico \\
\hline Revista masculina & $\begin{array}{l}\text { Livro de catecismo } \\
\text { Assinatura de }\end{array}$ & Revista técnica \\
\hline Revista de culinária & periódicos & Outros livros didáticos \\
\hline Revista informativa & & Dicionário \\
\hline Revista de informática & & Apostila \\
\hline Revista feminina & & Manual didático \\
\hline Revista teen & & Guia de vestibular \\
\hline Revista de decoração & & Apostila de supletivo \\
\hline Revista de televisão & & Livro paradidático \\
\hline Revista de animais & & Enciclopédia \\
\hline Revista de carros & & Livro e revista técnica \\
\hline Revista de saúde & & Livro pré-escolar \\
\hline Álbum e figurinhas & & Manual de vestibular \\
\hline Figurinhas de álbum & & Mensalidade de biblioteca \\
\hline \multicolumn{3}{|l|}{ Folheto } \\
\hline \multicolumn{3}{|l|}{ Folheto musical } \\
\hline \multicolumn{3}{|l|}{ Cruzadinha } \\
\hline \multicolumn{3}{|l|}{ Palavra cruzada } \\
\hline \multicolumn{3}{|l|}{ Revista de artesanato } \\
\hline \multicolumn{3}{|l|}{ Revista religiosa } \\
\hline Assinatura de jornal & & \\
\hline Assinatura de revista & & \\
\hline
\end{tabular}


Tabela A1: Média e desvio padrão das variáveis

\begin{tabular}{|c|c|c|c|c|c|c|}
\hline \multirow{2}{*}{ Variáveis } & \multicolumn{2}{|c|}{1996} & \multicolumn{2}{|c|}{2003} & \multicolumn{2}{|c|}{2009} \\
\hline & Média & D.P. & Média & D.P. & Média & D.P. \\
\hline \multicolumn{7}{|l|}{ Dependentes } \\
\hline Jornais e Revistas & 0,07 & 0,26 & 0,07 & 0,25 & 0,09 & 0,28 \\
\hline Livros & 0,09 & 0,29 & 0,19 & 0,39 & 0,13 & 0,34 \\
\hline Livros técnicos & 0,04 & 0,20 & 0,10 & 0,30 & 0,07 & 0,25 \\
\hline \multicolumn{7}{|l|}{ Independentes } \\
\hline Gasto per capita & 932,00 & $2.833,06$ & 846,81 & $1.160,47$ & 972,69 & $1.577,77$ \\
\hline Moradores & 4,61 & 2,21 & 4,27 & 1,92 & 3,90 & 1,78 \\
\hline Chefe & 0,40 & 0,49 & 0,35 & 0,48 & 0,38 & 0,48 \\
\hline Cônjuge & 0,20 & 0,40 & 0,22 & 0,42 & 0,23 & 0,42 \\
\hline Filhos & 0,30 & 0,46 & 0,33 & 0,47 & 0,31 & 0,46 \\
\hline Outros & 0,10 & 0,30 & 0,10 & 0,30 & 0,09 & 0,28 \\
\hline Sexo & 0,49 & 0,50 & 0,48 & 0,50 & 0,47 & 0,50 \\
\hline Chefe_trab & 0,88 & 0,49 & 0,83 & 0,38 & 0,79 & 0,41 \\
\hline Cônjuge_trab & 0,42 & 0,49 & 0,57 & 0,50 & 0,56 & 0,50 \\
\hline Filhos_trab & 0,36 & 0,48 & 0,46 & 0,50 & 0,43 & 0,49 \\
\hline Outros_trab & 0,34 & 0,47 & 0,48 & 0,50 & 0,43 & 0,50 \\
\hline Educação 3 & 0,10 & 0,31 & 0,11 & 0,32 & 0,09 & 0,29 \\
\hline Educação 7 & 0,33 & 0,47 & 0,35 & 0,48 & 0,28 & 0,45 \\
\hline Educação 12 & 0,45 & 0,50 & 0,47 & 0,50 & 0,48 & 0,50 \\
\hline Educação 15 & 0,12 & 0,32 & 0,07 & 0,26 & 0,15 & 0,35 \\
\hline Cartão & 0,21 & 0,41 & 0,26 & 0,44 & 0,35 & 0,48 \\
\hline Internet & 0,02 & 0,13 & 0,08 & 0,27 & 0,10 & 0,30 \\
\hline Idade & 35,12 & 16,69 & 33,69 & 16,03 & 36,20 & 16,90 \\
\hline Norte & 0,09 & 0,28 & 0,08 & 0,27 & 0,07 & 0,26 \\
\hline Nordeste & 0,36 & 0,48 & 0,32 & 0,47 & 0,26 & 0,44 \\
\hline Sudeste & 0,28 & 0,45 & 0,34 & 0,47 & 0,40 & 0,49 \\
\hline Sul & 0,14 & 0,34 & 0,19 & 0,39 & 0,12 & 0,33 \\
\hline Centro-Oeste & 0,14 & 0,34 & 0,08 & 0,27 & 0,14 & 0,35 \\
\hline
\end{tabular}

Fonte: Elaboração própria baseada nos dados da pesquisa. 